\title{
A bizarre self inflicted injury resulting in a "Near-Miss" in a Gynaecological case
}

\author{
Rachna Agarwal, AG Radhika, Bindiya Gupta, Gita Radhakrishnan \\ Correspondence: Dr Rachna Agarwal, Professor, Department of Obstetrics and \\ Gynaecology, UCMS and GTBH, Delhi, India; Email - rachna_anila@yahoo.co.in \\ Distributed under Creative Commons Attribution-Share Alike 4.0 International.
}

\begin{abstract}
A 32 year old, para 3 woman presented in shock and drowsy condition with bleeding per vaginum. On gaining consciousness, the patient revealed that she had chopped off some part of her gentalia and flushed it. Her previous treatment papers revealed she had been suffering uterine prolapse since last chid birth 3 years back. On examination, cervix could not be seen, and vaginal edges were seen bleeding. After patient stabilization, EUA showed a partially amputated cervix with retracted vaginal edges. A vaginal hysterectomy was done. On cut section of hysterectomy specimen, only $1 \mathrm{~cm}$ of cervix was identifiable, and uterus otherwise being normal on gross examination. The post operative period was uneventful. In view of extreme nature of affliction, a history of intoxication was obtained but denied by both husband and the patient. No history of prior psychiatric illness or symptomatology was reported. Psychiatric consultation revealed it to be a case of first episode of psychosis and accordingly antipsychotic treatment was started.
\end{abstract}

Keywords: Self mutilation, cervix, psychosis, genital mutilation.

The unusual self mutilation of genitalia can have bizarre presentation amounting to suicidal attempt. The psychological effects of prolapse are often missed by gynaecologists and may lead to extreme steps by patients with sexual disharmony. Although tremendous research has been done into the eitiology, pathophysiology and treatment modalities, the psychological effects of prolapse have not received due attention by the gynaecologists.

\section{Case report}

A para 3, lady presented to our emergency department in shock with feeble pulse and drowsy condition. Patient, who had a minor altercation with her husband in evening locked herself in bathroom, chopped off the prolapsed and flushed it. She was then found in drowsy state and brought to hospital by the husband. On gaining consciousness, patient revealed that she had been suffering uterine prolapse since past 2 years and was advised exercises by various clinicians. No other gynaecologic compliant was reported. She denied any history of urinary or bowel complaints. No history of prior psychiatric illness or symptomatology was reported by patient and husband. In view of extreme nature of affliction, a history of intoxication was obtained in complete confidence from the husband and also the patient when she gained complete consciousness. They both denied any such intoxication or substance abuse. All her deliveries were normal vaginal deliveries and youngest child was 3 year old.

Received: 6 th July 2017. Accepted: 6 th November 2017.

Agarwal R, Radhika AG, Gupta B, Radhakrishnan G. A bizarre self inflicted injury resulting in a "Near-Miss" in a Gynaecological case. The New Indian Journal of OBGYN. 2018; 4(2): 171 - 72. 
On examination cervix could not be seen, and vaginal edges were seen bleeding. Detailed examination was not allowed by patient due to pain. After adequate resuscitation and preliminary investigations, patient was taken up for examination in Operation Theatre. On examination cervix was seen partially amputated, vaginal edges retracted all around and subvaginal tissue was lacerated and friable. No major vessel or bleeder noted. Bladder and rectum integrity were confirmed by digital rectal examination and retrograde filling of bladder with saline. A step wise vaginal hysterectomy was done. Bilateral tubes and ovaries were noted normal. On cut section of hysterectomy specimen, only $1 \mathrm{~cm}$ of cervix was identifiable, and uterus otherwise being normal on gross examination. The post operative period was uneventful. Psychiatric consultation in the postoperative ward revealed a Hamilton depression rating score of 16 , hence confirming the diagnosis of major depression and the current episode was 3 month old.

\section{Discussion}

On review of literature, we found reports of genital mutilation in psychotic patients, especially schizophrenia and mania but no such instance was associated with depression. ${ }^{1-4}$ Habek et al had presented a bizarre case of attempted autosection of prolapsed genital organ by a demented 81-year-old women with chronic alcocholism. ${ }^{1}$ MacLean et al reported two cases of drastic form of selfmutilation in schizophrenic men. They had concluded based on review that psychosis, most probably schizophrenia, is associated with severe disturbance in body image, leading to the daring act of self-enucleation. ${ }^{4}$

In our patient there was no prior history of psychiatric illness. Moreover, no case of cervical self "amputation" is reported in literature. Whether this behavior of our patient reflects a psychosomatic effect of disease prolapsed, effect of prolapsed on disturbed body image or it should be considered a part of spectrum of genital mutilation consequent upon psychiatric illness needs more elucidation. Whereas the effect of prolapse has been studied on the sexual well being and quality of life of patients, little emphasis has been placed on the general mental well being. We hence need further objective evidence of psychological effects of prolapse and incorporate it in its management.

Pelvic floor dysfunction is a multi-faceted problem because it has both anatomical and functional aspects. Although pelvic organ prolapse had an effect on some aspects of sexuality. Sexual function may be more related to a woman's perception of her body image than to actual topographical changes from prolapse.

\section{Conflict of interest: None. Disclaimer: Nil.}

\section{References}

1.Habek D, Barbir A, Galovic J, Habek JC. Autosection of the prolapsed uterus and vagina. Eur J Obstet Gynecol Reprod Biol. 2002; 103(1): 99-100.

2.Standage KF, Moore JA, Cole MG. Self-mutilation of the genitalia by a female schizophrenic. Can Psychiatr Assoc J. 1974; 19(1): 17-20.

3.Reich LH, Wehr T. Female genital self-mutilation. Obstet Gynecol. 1973; 41(2): 239-42.

4.MacLean G, Robertson BM. Self-enucleation and psychosis - Report of two cases and discussion. Arch Gen Psychiatry. 1976; 33(2): 242-9.

\section{Rachna Agarwal ${ }^{1}$, AG Radhika ${ }^{2}$, Bindiya Gupta ${ }^{3}$, Gita Radhakrishnan ${ }^{4}$ \\ ${ }^{1}$ Professor, ${ }^{2}$ Gynaecologist, ${ }^{3}$ Assistant Professor, ${ }^{4}$ Dir. Prof. \& Unit Head; Department of Obstetrics and Gynaecology, UCMS and GTBH, Delhi, India}

